\title{
Analyzing the Metrics of the Perceptual Space in a New Multistage Physiological Colour Vision Model
}

\section{Elísabet Chorro, ${ }_{1}^{1 *}$ Francisco Miguuel Martínez-Verdú, ${ }^{1}$ Dolores de Fez, ${ }^{1}$ Pascual Capilla, ${ }^{2}$ Maria José Luque ${ }^{2}$}

\author{
${ }^{1}$ Department of Optics, Pharmacology and Anatomy, University of Alicante, 03690 Alicante, Spain \\ ${ }^{2}$ Department of Optics, University of Valencia, 46100 Burjassot, Spain
}

Received 7 January 2008; revised 9 May 2008; accepted 3 July 2008

\begin{abstract}
In this work, the metric of a new multistage colour vision model, ATTD05, is assessed and a new colour difference formula is suggested. Firstly, the uniformity of the ATTD05 colour space was compared with that of CIECAM02 for some Munsell samples, because if the model yields a uniform perceptual space, we will be able to implement a colour difference formula as a Euclidian distance between two points. Secondly, we developed a new space based on the perceptual descriptors of the model: brightness, hue, colourfulness, and saturation. After that, we calculated the free parameters of the space that better fit the measured and experimental data of two datasets (small-magnitude and large-magnitude colour differences), by minimizing the performance factor $(P F / 3)$. Finally, we compare colour differences calculated for ATTD05 and for other models. The PF/3 and the STRESS parameters were used to decide which model predicts better perceptual differences and, therefore, which model was the more uniform. (๑ 2009 Wiley Periodicals, Inc. Col Res Appl, 00, 000-000, 2009; Published online in Wiley InterScience (www.interscience.wiley. com). DOI 10.1002/col.20524
\end{abstract}

Key words: colour appearance models; neural model; colour difference metrics; uniform colour space

\section{INTRODUCTION}

One purpose of colour vision models is to predict perceptual descriptors of colours under different viewing condi-

\footnotetext{
*Correspondence to: Elísabet Chorro (e-mail: elisabet.chorro@ua.es).

Contract grant sponsor: Spanish Ministry for Education and Science; contract grant number: DPI2005-08999-C02-02 and DPI2008-06455C02-02.
}

() 2009 Wiley Periodicals, Inc. tions. There are two main types of colour vision models: colour appearance models ${ }^{1-7}$ and neural models. ${ }^{8-17}$ Both predict perceptual descriptors, but the difference between them is that neural models also try to follow the stages of the visual system. However, quite often evaluating colour differences between two samples is more important than obtaining numerical values of perceptual descriptors. Initially, separate models ${ }^{18-24}$ were developed to fit colour appearance and colour difference data. However, the perfect solution would be to obtain a single model, which could reproduce both perceptual descriptors and colour differences. For instance, CIECAM $02^{22}$ is the latest colour appearance model adopted by the CIE, and recently Luo et al. ${ }^{23,24}$ have published a colour difference formula for this model. Our aim is to determine whether a good colour difference formula can be obtained from ATTD05 $^{25,26}$ (see Appendix A), which is a neural multistage colour vision model. To obtain such a formula, we follow the same strategy as Luo et al. with CIECAM02.

In this article, we briefly describe the ATTD05 neural model. After that, using a set of samples from the Munsell Atlas, which we assume to have an Euclidian metric (but see Indow ${ }^{27}$ for details), we study the uniformity of the perceptual space of the model in comparison with the perceptual space of CIECAM02, because if the model yields a uniform perceptual space, we will be able to implement a colour difference formula as a Euclidian distance between two points.

Secondly, a colour difference formula is implemented using the last stage descriptors of ATTD05 and three free scaling parameters. The minimization of the performance factor $^{28}(\mathrm{PF} / 3)$, which is a statistical parameter that measures the goodness of fit, was used to calculate these free parameters to fit small-magnitude and large-magnitude difference datasets. These datasets are the same used by 


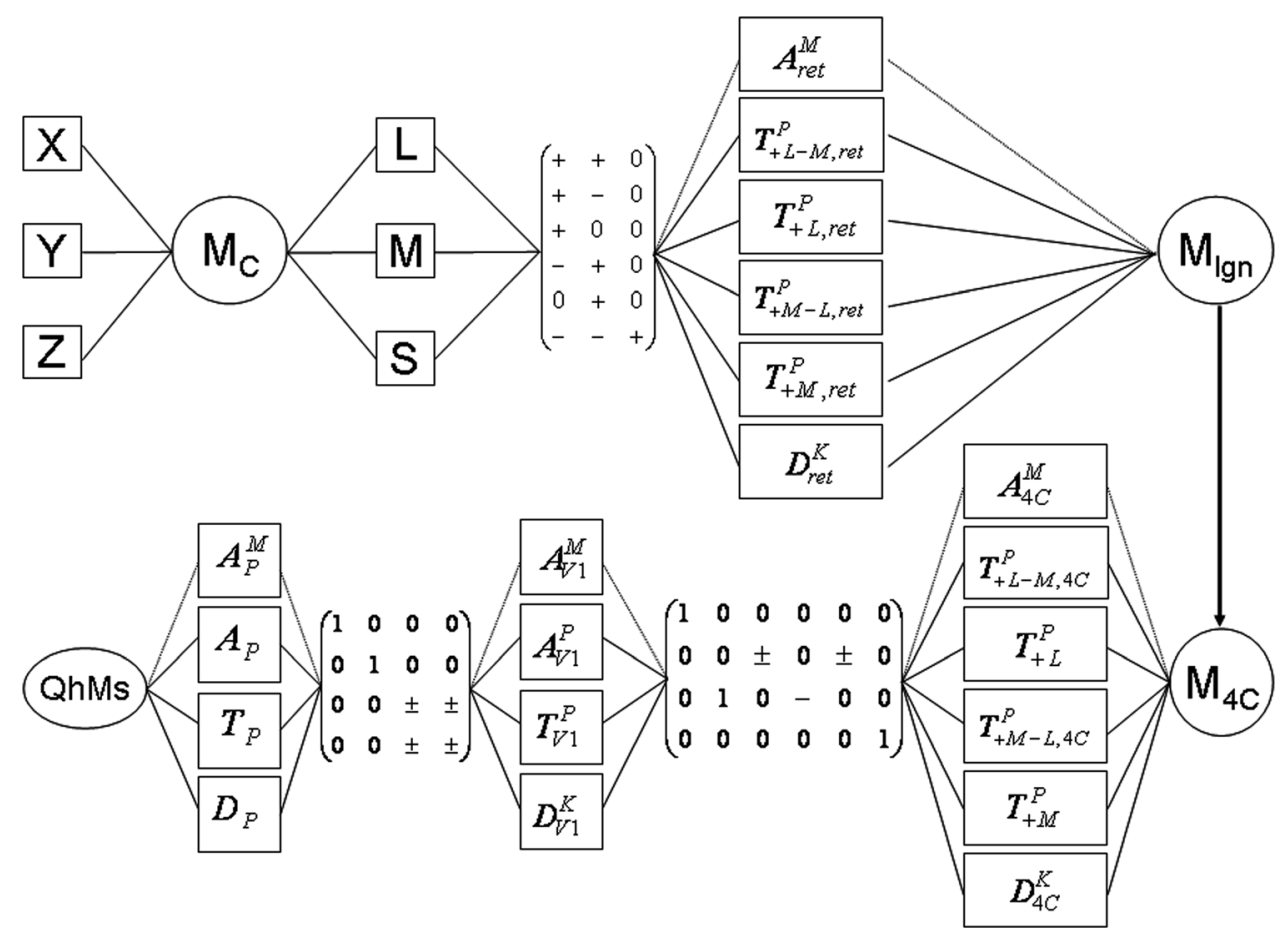

FIG. 1. Schema of the ATTD05 model. Precortical and cortical stages. We write $X(C)$ to denote the value of any colour descriptor $X$ for stimulus $C$. Sets of descriptors (or responses), $[A(C), B(C), \ldots, X(C)]$, at a given stage appear as $R_{\text {stage }}(C)$ for short and the $j$ th descriptor is referred to as $R_{\text {stage }, j}(C)$. To distinguish between descriptors with the same name but obtained at different stages of the model, we use a sub-index for the stage and a super-index for the pathway (Magno-, Parvo- or Konio-cellular). Finally, matrix elements are referred to as $M_{\text {row,column. }}$ Variables are defined in the text. $W_{\text {Con }}$ and $W_{\text {ret }}$ are diagonal scaling matrixes, $\Gamma_{\text {con }}$ is a diagonal matrix with gains, $K_{\text {ret }}$ and $K_{V 1}$ are diagonal matrixes with subtractive reductions. Variables $\sigma_{\mathrm{Con}}, \gamma_{\mathrm{Con}}$ and $\sigma_{\text {ret }}$ are additional free parameters of the model and $n=0.7$. Symbols,+- and \pm in each matrixes indicate the elements that, with or without the sign, are free parameters of the model.

Luo et $a l .^{23,24}$ The small-magnitude colour differences (SCD) were used to develop the CIE 2000 colour difference formula CIEDE2000. ${ }^{29}$ On the other hand, the largemagnitude colour differences (LCD) were accumulated by several authors for other works: Zhu et al., ${ }^{30}$ OSA, ${ }^{31}$ Guan and Luo, ${ }^{32}$ BFDB, ${ }^{33}$ Pointer and Attridge, ${ }^{34}$ and Munsell. ${ }^{35,36}$

Finally, we compared colour differences predicted by both models with perceptual colour differences. For that, we calculated the performance factor ${ }^{28}(\mathrm{PF} / 3)$ and the standardized residual sum of squares ${ }^{37}$ (STRESS), which are used to compare different models ${ }^{28,29,38}$ and so we can decide which model better predicts perceptual colour differences.

\section{DESCRIPTION OF ATTD05}

ATTD05 25,26 is a neural model that tries to predict the perceptual descriptors of colours under different viewing conditions, following the stages of visual system. A schema of this model including the relevant formulae, appears in Fig. 1, and a library for Matlab ${ }^{\circledR}$ may be downloaded from the web. ${ }^{39}$ The numerical values of the free parameters of the model were determined by minimizing a coefficient of agreement between a small set of experimental data and the predictions of the model for this data. ${ }^{25,26}$ The training data set did not include colour difference data.

The ATTD05 model computes the perceptual descriptors of an object, $C$, from its CIEXYZ tristimulus values, $X Y Z(C)$, and those of the background that surrounds it. The $X Y Z$ values are normalized so that $\mathrm{Y}$ is the retinal illumination in trolands. Responses of the L, M and Scones, $R_{\mathrm{Con}, j}(C)$, are the result of a linear stage (computed from the Smith and Pokorny ${ }^{39}$ fundamentals normalized to one ${ }^{40}$ ), followed by a gain-control mechanism and a nonlinearity of the Naka-Rushton type. ${ }^{41}$ These responses are combined to yield, after another NakaRushton type nonlinearity, an achromatic channel, $\left(A_{\text {ret }}^{\mathrm{M}}\right)$, two opponent channels with red-green opponency but different polarities $\left(T_{+\mathrm{L}-\mathrm{M}, \mathrm{ret}}^{\mathrm{P}}\right.$ and $\left.T_{+\mathrm{M}-\mathrm{L}, \mathrm{ret}}^{\mathrm{P}}\right)$ (hence the "TT" in the name of the model) and one opponent channel with blue-yellow opponency $\left(D_{\text {ret }}^{\mathrm{K}}\right)$. For the achromatic channel, the nonlinearity is preceded by a subtractive adaptation mechanism. We assume that these channels would be supported, respectively, by Magno (M) cells with Type III receptive fields, Parvo (P) cells with Type I receptive fields (polarity $+\mathrm{L}-\mathrm{M}$ mediated by $\mathrm{L}$-on center cells and polarity $+\mathrm{M}-\mathrm{L}$ mediated $\mathrm{M}$-on center cells) and Konio (K) cells with type II receptive fields. ${ }^{42-49}$ For computational purposes, we need at this level to isolate the excitatory parts of $T_{+\mathrm{L}-\mathrm{M} \text {,ret }}^{\mathrm{P}}$ and $T_{+\mathrm{M}-\mathrm{L}, \text { ret }}^{\mathrm{P}}$, which we denote $T_{+\mathrm{L}, \mathrm{ret}}^{\mathrm{P}}$ and $T_{+\mathrm{M}, \mathrm{ret}}^{\mathrm{P}}$. The response of the four real 
channels plus these two auxiliary variables are denoted $R_{\text {ret }, j}(C)$. Because cells with basically the same spectral properties exist at ganglion cell level, in the LGN and layer 4 of the striate cortex, ${ }^{42,49,50}$ the output of these three stages of the model-though each labelled with a different subscript, identifying the stage they belong tois identical. The responses at the $4 \mathrm{C}$ stage are subsequently combined to yield an achromatic $\left(A_{\mathrm{V} 1}^{\mathrm{P}}\right)$, a redgreen $\left(T_{\mathrm{V} 1}^{\mathrm{P}}\right)$, and a blue-yellow $\left(D_{\mathrm{V} 1}^{\mathrm{K}}\right)$ intermediate channels. The responses of these channels $R_{\mathrm{V} 1}(C)$, are modified by the responses to the background by means of a subtractive process. We assume that this stage would be mediated by Type III and double-opponent cells in the blobs of layers 2 and 3 of the striate cortex.$^{50-53}$ Finally, the responses of these intermediate mechanisms are recombined to generate the responses of the achromatic $\left(A_{\mathrm{P}}\right)$, red-green $\left(T_{\mathrm{P}}\right)$, and blue-yellow $\left(D_{\mathrm{P}}\right)$ perceptual mechanisms, from which descriptors for brightness, hue, colourfulness, and saturation may be computed.

\section{METHODS}

\section{Uniformity of the Perceptual Space of the ATTD05 Model}

As we have said before, we need also to calculate colour differences between two samples. For that, we shall study the uniformity of the $\left(T_{\mathrm{P}}, D_{\mathrm{P}}\right)$ plane of ATTD05, in comparison with CIECAM02, because if the model yields a uniform perceptual space we will be able to implement a colour difference formula as a Euclidian distance between two points. To do that, we shall use a set of samples from the Munsell Atlas, because if a colour space is uniform, constant hue loci should appear equally spaced in angle and constant Chroma loci as equally spaced circles, and their common center ought to be achromatic. To measure how well these conditions are fulfilled, we have defined the following set of parameters:

1. The circularity index of the $C_{\mathrm{M}}$ Chroma ring for value $V, \varepsilon_{\mathrm{V}, \mathrm{C}_{\mathrm{M}}}$

2. The Chroma spacing index, $\varepsilon_{\mathrm{V}, \mathrm{R}}$

3. The hue spacing index $\varepsilon_{\mathrm{H}, \mathrm{V}, \mathrm{C}_{\mathrm{M}}}$

4. The dispersion index of the centers of gravity, $\varepsilon_{\mathrm{V}, \mathrm{e}}$

Definitions of all these parameters are given in Appendix A and are similar to other previously used in the literature. ${ }^{54}$ In a perfectly uniform space, the circularity indexes, the Chroma and hue spacing indexes, and the dispersion index of the centers of gravity are zero. The lower these values, the more uniform is the space. Distances used to compute these parameters, for a given Value, have as origin the position of the global center of gravity, $\operatorname{TD}\left(C_{0}\right)$, of the Munsell samples of that Value. If we had chosen as origin the achromatic point of the model, Chroma loci centered on a different point of the space might be perfectly circular but would yield nonzero circularity indexes. Note that the length of the vector $\operatorname{TD}\left(C_{0}\right)$ measures only how different from the achromatic point of the model is the center of the Munsell rings.
This difference ought to be small, because Munsell samples are equally spaced from a sample perceived as achromatic.

\section{New ATTD05-Based Uniform Colour Space}

If ATTD05 is a uniform colour space, colour differences may be computed as the distance between two points with a diagonal metric, that is, with weight factors in each coordinate. So, we propose this equation to evaluate colour differences in ATTD05:

$$
\Delta E=\sqrt{\left(c_{1} \cdot \Delta A_{\mathrm{p}}\right)^{2}+\left(c_{2} \cdot \Delta T_{\mathrm{p}}\right)^{2}+\left(c_{3} \cdot \Delta D_{\mathrm{p}}\right)^{2}}
$$

Coefficients $c_{1}, c_{2}$, and $c_{3}$ are constants that must be computed to fit experimental results. Following the same strategy as earlier authors, the best coefficients $c_{i}$ must minimize the value of the performance factor, ${ }^{24,28}$ which measures the goodness of fit. For a perfect agreement between the visual results and predictions, $\mathrm{CV}$ and $V_{\mathrm{AB}}$ should equal zero, gamma should equal one and so the performance factor should be zero.

\section{Testing the Colour-Difference Equation for ATTD05}

Up to this point, we have studied the uniformity of the perceptual space of ATTD05 and we have developed a colour difference formula based on the assumption that this model gives a uniform colour space. To test the colour difference formula, we have used two datasets to calculate two parameters, which are useful to compare predictions made with our colour difference formula and with other models. These parameters are the performance factor, ${ }^{24,28}(\mathrm{PF} / 3)$ and the standardized residual sum of squares $^{37}$ (STRESS). Both are used to compare models, but the main difference between PF/ 3 and STRESS is that $\mathrm{PF} / 3$ only evaluates the agreement between experimental and theoretical colour differences but cannot indicate the statistical significance of the difference between two colour difference formulas or spaces tested. To solve this problem, the statistical significance must be evaluated by a statistical test, the $F$ test, for instance. On the other hand, STRESS is simpler and allows inferences on the statistical significance of two colour-difference formulae for a given set of visual data. To do that, we only have to calculate de $F$-test as the quotient between STRESS modelA $_{\text {in }}$ and $\mathrm{STRESS}_{\text {modelB}}$.

The null hypothesis we have used for the $F$-test is the one used by Luo and coworkers, that is, "there is no significant differences between the formulae of Model A and Model B." Therefore, when the $F$ value is lower than a critical value $F_{\mathrm{C}}$, we accept the null hypothesis and hence Model A is significantly different than Model B. After that we may decide which the better model is by comparing the $\mathrm{PF} / 3$ or STRESS values. The critical value $F_{\mathrm{C}}$ depends on the dataset, for instance, it is 0.937 for a twotailed $F$ distribution with $95 \%$ confidence level and 3657 degrees of freedom, which are the number of colours from the SCD dataset, and 0.930 for 2954 degrees of free- 

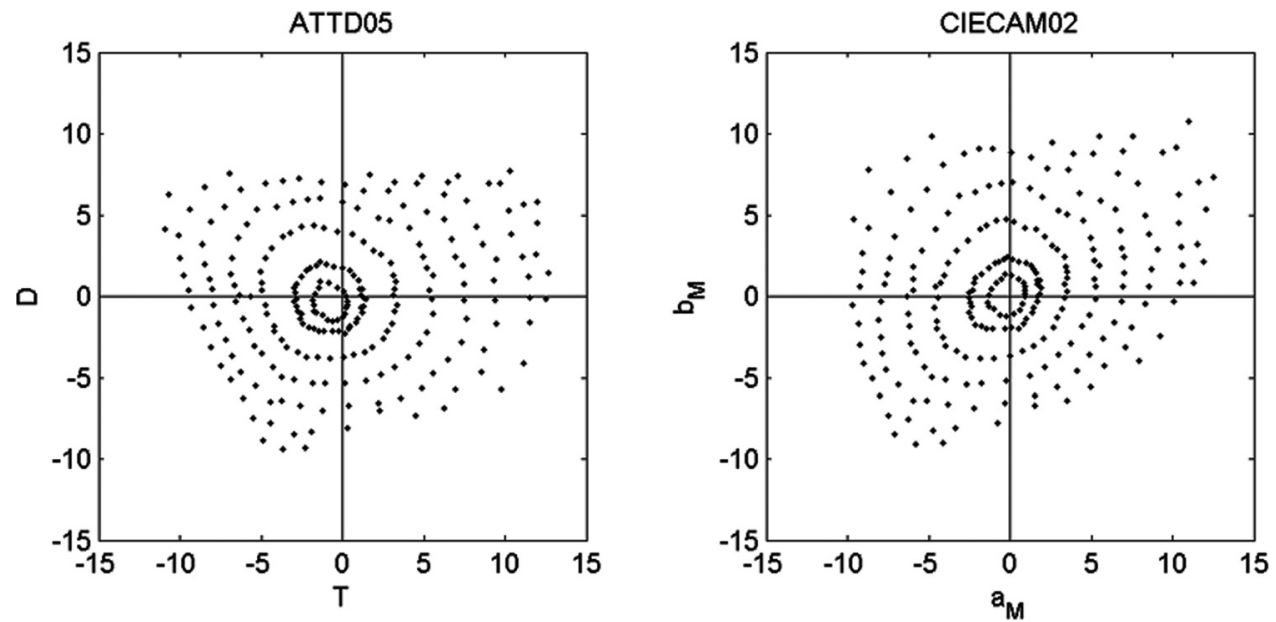

FIG. 2. Samples of constant Munsell Value 5 plotted on the perceptual plane of the ATTD05 and CIECAM02 models.

dom, which are the number of colours from the LCD dataset.

\section{RESULTS}

\section{Uniformity of the Perceptual Space of the ATTD05 Model}

We have chosen the samples with constant Values, 3, 5, and 7 of the Munsell atlas. Because the conclusion reached by all Values is similar, we show a single example in the perceptual spaces of CIECAM02 and ATTD05

(Fig. 2), which show that both spaces seem fairly uniform. Particularly, the rings in ATTD05 look more circular, although we can see that the center of the rings is a bit shifted away from the origin of the space. For quantitative comparisons, we have used a set of four parameters. ${ }^{54}$ Histograms of the parameters for the Munsell samples with value 3,5, and 7 calculated with ATTD05 and

F3-F6 CIECAM02, under illuminant C, are shown in Figs. 3-6. Lower circularity index occurs when rings of constant
Munsell Chroma are more circular and, as we can conclude from Fig. 3, the rings of constant Munsell Chroma in ATTD05 are more circular than in CIECAM02, except for Chroma 6 (the higher Chroma considered) in all Values. In the same way, seeing Fig. 4, we can conclude that hue spacing is more uniform in ATTD05 than in CIECAM02 and this is confirmed by the lower values of the hue spacing index yielded by ATTD05 for all Values and Chromas. The Chroma spacing index (Fig. 5) is also better in ATTD05 for all values. The Wilcoxon signed-rank test shows, however, that the differences between models in the hue spacing indexes found are not statistically significant (significance values greater than 0.05), whereas for the circularity index the differences are either not significant or when they are (significance values below 0.05), it is ATTD05 which yields the better results, with the single exception of the Value $=2$ and Chroma $=1$ ring (not shown). The model that yields the smallest eccentricity of the centers of gravity varies with Chroma, whereas for value 3 ATTD05 yields consistently larger values for all Chroma rings. As a result, the dispersion
Value 3

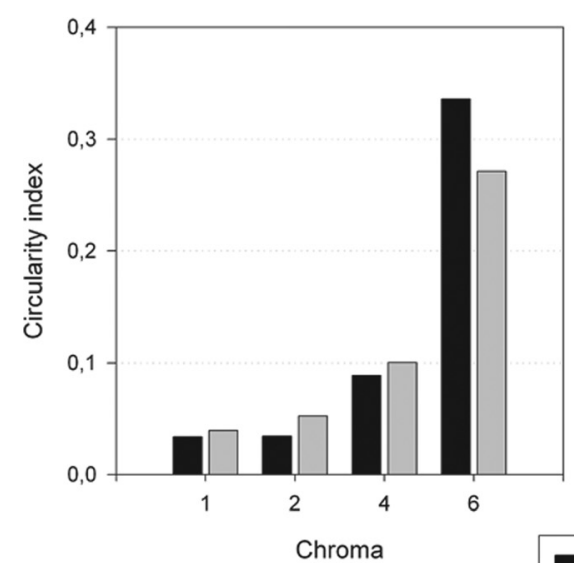

Chroma
Value 5

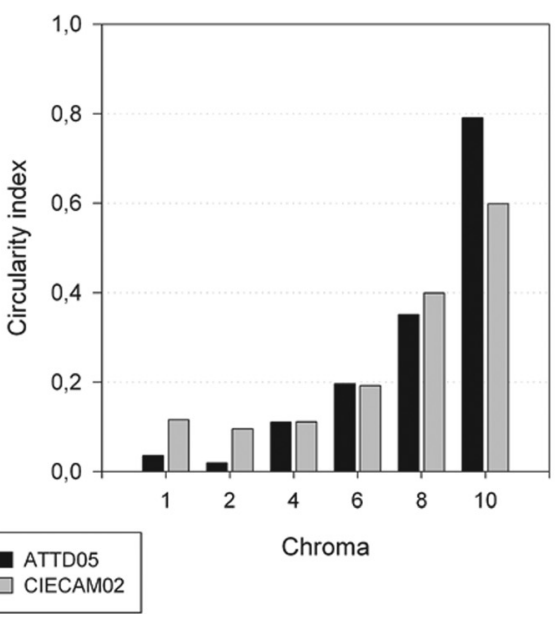

Value 7

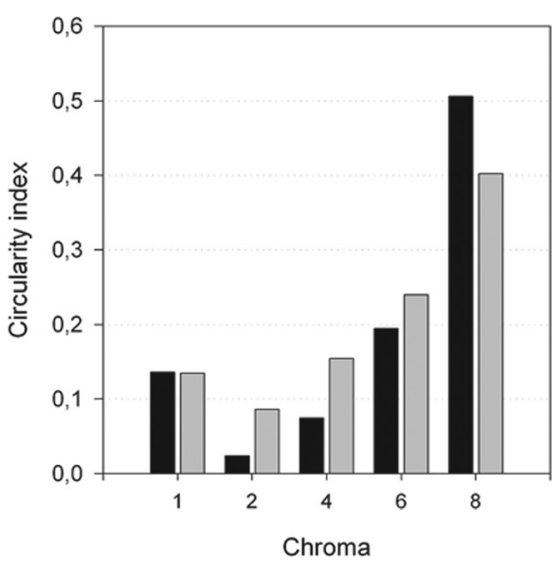

FIG. 3. Circularity indexes for the different chroma rings and values. 
Value 3

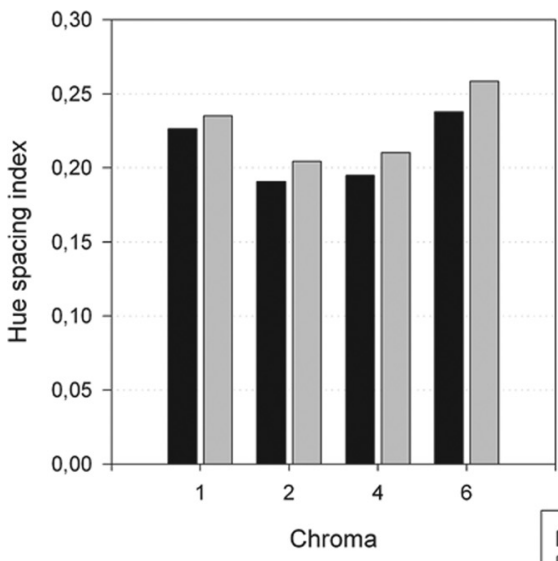

Value 5

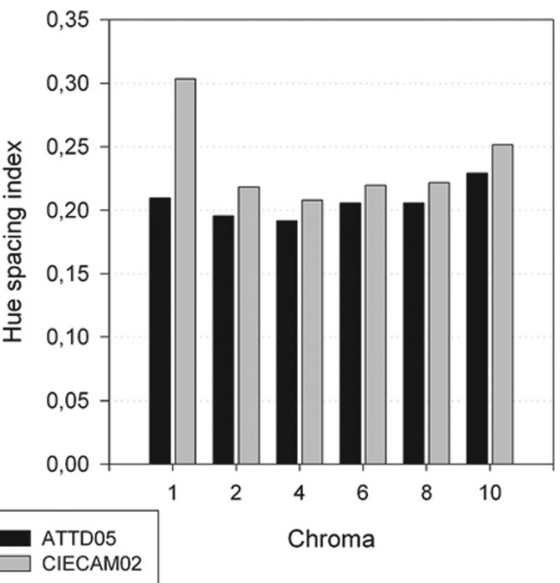

Value 7

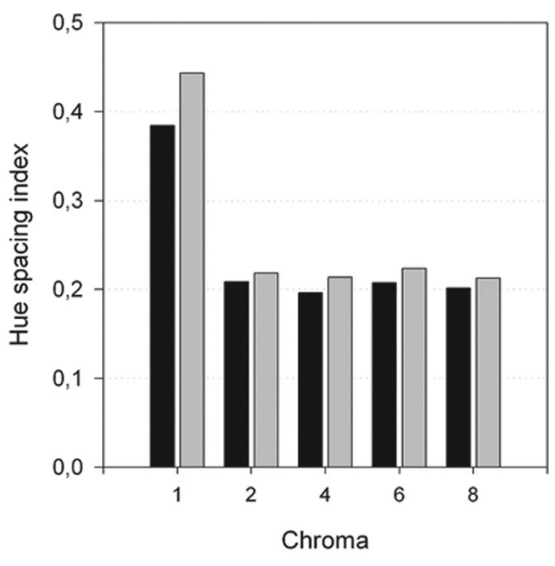

FIG. 4. Hue spacing indexes for the different chroma rings and values.

index, which globally quantifies the stability of the centers of gravity, is notably worse for ATTD05 at the lowest value $(V=3)$, and equal to that of CIECAM02 in the other cases (see Fig. 6). The position of the center of gravity for each Munsell value, $\operatorname{TD}\left(C_{0}\right)$, in ATTD05, is shifted from the origin $\sim 1 \Delta E^{*}$ unit, just as the centers of gravity for each Chroma ring, $\operatorname{TD}\left(C_{0, C_{\mathrm{M}}}\right)$. However, these shifts are approximately of the same order than for the CIECAM02 model, except for Munsell value 3, where, although the shift is the smallest, the difference between the two models is around a factor 3 .

\section{New ATTD05-Based Uniform Colour Space}

The experimental data chosen to fit the coefficients are two datasets including small-magnitude and large-magnitude colour differences, previously used by Luo et $a l^{29}$ The small-magnitude colour differences (SCD) were used to develop the CIE 2000 colour difference formula CIEDE2000 29 and include 3657 sample pairs with an average of $2.6 \Delta E^{*}$ units. The large-magnitude colour differences (LCD) were accumulated by several authors:

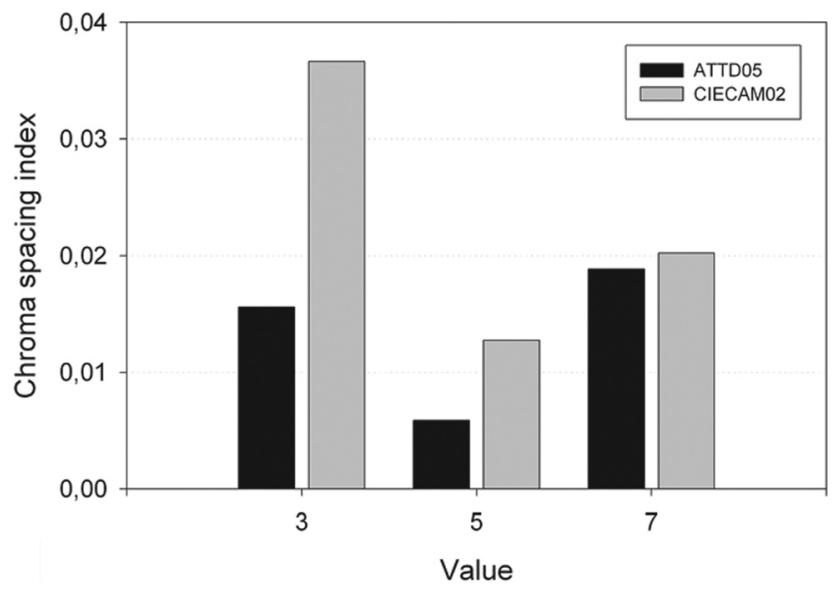

FIG. 5. Choma spacing indexes for the different values.
Zhu et al., ${ }^{31}$ OSA, ${ }^{32}$ Guan and Luo, ${ }^{33}$ BFDB, ${ }^{34}$ Pointer and Attridge ${ }^{35}$ and Munsell ${ }^{36,37}$ and include 2954 sample pairs with an average of $10 \Delta E^{*}$ units.

On the other hand, following the same strategy as earlier authors, the best coefficients $c_{i}$ must minimize the value of the performance factor, which measures the goodness of fit. This method has been used to calculate the coefficients, $C_{i}$, with both datasets, LCD and SCD. The results are shown in Table I. Finally, we only use one of them because the performance factors with these two coefficients, $C_{i, \mathrm{LCD}}$ and $C_{i, \mathrm{SCD}}$, are very similar for both datasets.

\section{Testing the Colour-Difference Equation for ATTD05}

We obtained the same conclusions using the $\mathrm{PF} / 3$ or the STRESS factor, for this reason only one of them are shown in this work. Table II summarizes the STRESS values using the SCD and the LCD datasets. From Tables III and IV we can conclude that ATTD05 predicts better the experimental data than CIELAB, CIE94 and CIEDE2000.

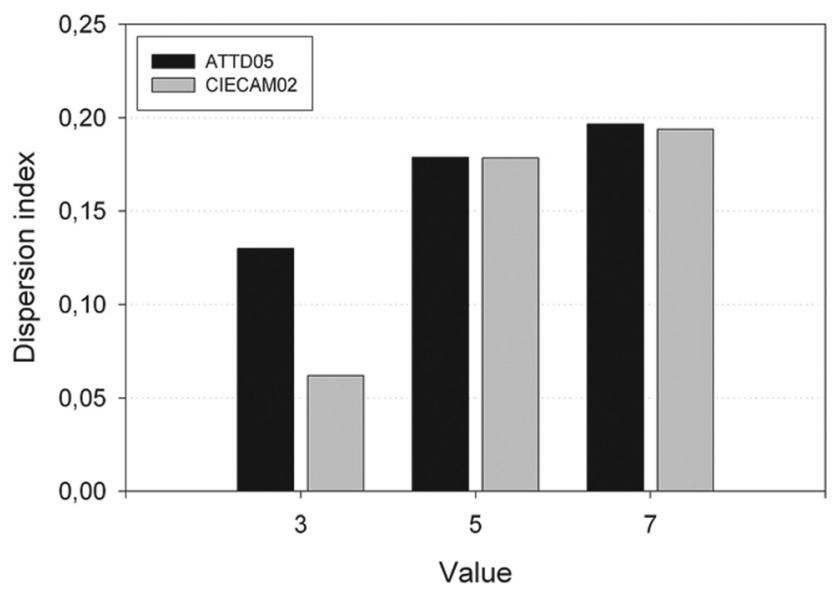

FIG. 6. Dispersion indexes for the different values. 
TABLE I. The coefficients, $C_{i}$, that minimize the value of the performance factor.

\begin{tabular}{lcccc}
\hline & $C_{1}$ & $C_{2}$ & $C_{3}$ & $\mathrm{PF} / 3$ \\
\hline Data SCD & 0.74 & 0.92 & 1.02 & 45.95 \\
Data LCD & 0.83 & 1 & 1.16 & 25.57 \\
\hline
\end{tabular}

\section{CONCLUSIONS}

We have analyzed the uniformity of ATTD05 and have compared it with the uniformity of CIECAM02, by studying loci of perceptually equally spaced samples from the Munsell Atlas, and calculating parameters that evaluate circularity, hue-spacing and Chroma-spacing properties, and the stability of the centers of gravity of constant Chroma rings. Because for ATTD05, loci of constant Chroma are more circular than for CIECAM02 (with the exception of the highest Chroma for all Values), the Chroma spacing index for all values and the hue spacing indexes for all Chromas and Values are lower in ATTD05 (but the differences between both models are not statistically significant for the hue spacing index), and the dispersion index of the centers of gravity for the rings for a given value are in the same order in both models (except for the lower Value), we conclude that the perceptual space of ATTD05 has a higher degree of uniformity than that of CIECAM02. Consequently, a useful colour difference formula could be implemented. Therefore, we have proposed a colour difference formula for ATTD05 with three constant coefficients, determined by minimization of the performance factor.

Finally, we have tested the colour difference formula's predictions with two datasets, SCD and LCD, as well as the performance factor and the STRESS parameter. The results have shown that, when we use the SCD dataset, ATTD05 predicts better the experimental data than CIE$\mathrm{LAB}$, but not better than the other models. Besides, they show that when we use the LCD dataset, ATTD05 predicts better the experimental data than CIELAB and CIE94 and CIEDE2000. So, although the ATTD05 perceptual space is more uniform than CIECAM02 for tests based on Munsell samples, we still have to keep on looking for a suitable colour difference equation. But, in any case, the colour differences predicted by the ATTD05

TABLE II. Standardized residual sum of squares (STRESS) for different colour vision models.

\begin{tabular}{llll}
\hline $\begin{array}{l}\text { Tested using } \\
\text { the combined } \\
\text { SCD data sets }\end{array}$ & STRESS & $\begin{array}{c}\text { Tested } \\
\text { using the } \\
\text { combined LCD } \\
\text { data sets }\end{array}$ & STRESS \\
\hline CIELAB & 0.4424 & CIELAB & 0.2725 \\
CIE94 & 0.3243 & CIE94 & 0.2406 \\
CIEDE2000 & 0.3088 & CIEDE2000 & 0.2794 \\
CAM02-SCD & 0.2878 & CAM02-LCD & 0.2010 \\
ATTD05 & 0.3737 & ATTD05 & 0.2210 \\
\hline
\end{tabular}

TABLE III. The $F$-test results $\left(F=\right.$ STRESS $_{\text {modelA }}$ /

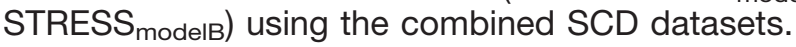

\begin{tabular}{lccccc}
\hline $\begin{array}{c}\text { ModelA } \\
\text { ModelB }\end{array}$ & CIELAB & CIE94 & CIEDE2000 & CAM02-SCD & ATTD05 \\
\hline CIELAB & & 1.364 & 1.433 & 1.537 & 1.187 \\
CIE94 & 0.733 & & 1.050 & 1.127 & 0.870 \\
CIEDE2000 & 0.698 & 0.952 & & 1.073 & 0.828 \\
CAM02-SCD & 0.651 & 0.888 & 0.932 & & 0.772 \\
ATTD05 & 0.843 & 1.149 & 1.207 & 1.295 & \\
\hline
\end{tabular}

Critical value is 0.937 for a two-tailed $F$ distribution with $95 \%$ confidence level and 3657 degrees of freedom.

TABLE IV. The $F$-test results ( $F=$ STRESS $_{\text {modelA }}$ / STRESS modelB$_{\text {) }}$ using the combined LCD datasets.

\begin{tabular}{lccccc}
\hline $\begin{array}{l}\text { ModelA } \\
\text { ModelB }\end{array}$ & CIELAB & CIE94 & CIEDE2000 & CAM02-SCD & ATTD05 \\
\hline CIELAB & & 1.133 & 0.975 & 1.356 & 1.233 \\
CIE94 & 0.883 & & 0.861 & 1.197 & 1.089 \\
CIEDE2000 & 1.025 & 1.161 & & 1.391 & 1.264 \\
CAM02-SCD & 0.737 & 0.835 & 0.719 & & 0.909 \\
ATTD05 & 0.811 & 0.919 & 0.791 & 1.100 & \\
\hline
\end{tabular}

Critical value is 0.930 for a two-tailed $F$ distribution with $95 \%$ confidence level and 2954 degrees of freedom.

model be not significant different than that of the CIECAM02 model.

\section{APPENDIX A}

Munsell Chromas and Munsell Values of the samples will be specified, when necessary, by subscripts $C_{\mathrm{M}}$ and $V$, respectively. For comparison purposes, the values of $T_{\mathrm{p}}$ and $D_{\mathrm{p}}$ and their equivalents in CIECAM02 $(\mathrm{a}, \mathrm{b})$ were normalized, for each Value, in such a way that the mean distance between the samples of the Munsell Chroma 6 locus to their own "center of gravity" is six, that is, for any colour $C_{i}$ of the Munsell Atlas, with perceptual descriptors $\operatorname{TD}_{\mathrm{P}}\left(C_{i}\right)=\left[T_{\mathrm{P}}\left(C_{i}\right), D_{\mathrm{P}}\left(C_{i}\right)\right]$ in the Chromaticity plane, the normalized descriptors $\operatorname{TD}\left(C_{i}\right)=$ $\left[T\left(C_{i}\right), D\left(C_{i}\right)\right]$ are defined as follows:

$$
\mathrm{TD}\left(C_{i}\right)=\frac{6}{R_{\mathrm{V}, \mathrm{C}_{\mathrm{M}}=6}} \cdot \mathrm{TD}_{\mathrm{P}}\left(C_{i}\right)
$$

where the mean radius of the Munsell Chroma 6 $\left(C_{\mathrm{M}}=6\right)$ ring for the $V$ Value considered, $R_{\mathrm{V}, \mathrm{C}_{\mathrm{M}}=6}$, is given by:

$$
R_{\mathrm{V}, \mathrm{C}_{\mathrm{M}}=6}=\frac{1}{N_{\mathrm{V}, \mathrm{C}_{\mathrm{M}}}=6} \cdot \sum_{j=1}^{N_{\mathrm{V}, \mathrm{C}_{\mathrm{M}}=6}}\left\|\operatorname{TD}_{\mathrm{P}}\left(C_{j, \mathrm{C}_{\mathrm{M}}=6}\right)-\mathrm{TD}_{\mathrm{P}}\left(C_{0, \mathrm{C}_{\mathrm{M}}=6}\right)\right\|
$$

$N_{\mathrm{V}, \mathrm{C}_{\mathrm{M}}=6}$ is the number of samples, $C_{j, \mathrm{C}_{\mathrm{M}}=6}$, in the Chroma 6 ring for the considered Value, and $\operatorname{TD}_{\mathrm{P}}\left(C_{0, \mathrm{C}_{\mathrm{M}}=6}\right)=\left[T_{\mathrm{P}}\left(C_{0, \mathrm{C}_{\mathrm{M}}=6}\right) \quad D_{\mathrm{P}}\left(C_{0, \mathrm{C}_{\mathrm{M}}=6}\right)\right]$ is the vector defining its "center of gravity", $C_{0, C_{\mathrm{M}}=6}$, that is:

$$
\operatorname{TD}_{\mathrm{P}}\left(C_{0, \mathrm{C}_{\mathrm{M}}=6}\right)=\frac{1}{N_{\mathrm{V}, \mathrm{C}_{\mathrm{M}}=6}} \cdot \sum_{j=1}^{N_{\mathrm{V}, \mathrm{C}_{\mathrm{M}}=6}} \operatorname{TD}_{\mathrm{P}}\left(C_{j, \mathrm{C}_{\mathrm{M}}=6}\right)
$$


For each Munsell Value, the center of gravity, $\operatorname{TD}\left(C_{0}\right)$, of the normalized $T D$ descriptors is computed with Eq. (A4):

$$
\mathrm{TD}\left(C_{0}\right)=\frac{1}{N_{\mathrm{V}}} \cdot \sum_{j=1}^{N_{\mathrm{V}}} \mathrm{TD}\left(C_{j}\right)
$$

where $N_{V}$ is the total number of samples $C_{j}$ for the Value $V$. The radius of any sample corresponding to that Value is calculated as a distance to this center:

$$
R\left(C_{j}\right)=\left\|\mathrm{TD}\left(C_{j}\right)-\mathrm{TD}\left(C_{0}\right)\right\|
$$

\section{Circularity, Chroma Spacing, and Hue Spacing}

The mean radius, $R_{\mathrm{V}, \mathrm{C}_{\mathrm{M}}}$, and the circularity coefficient, $\varepsilon_{\mathrm{V}, \mathrm{C}_{\mathrm{M}}}$, of each Chroma ring are computed as follows:

$$
\begin{gathered}
R_{\mathrm{V}, \mathrm{C}_{\mathrm{M}}}=\frac{1}{N_{\mathrm{V}, \mathrm{C}_{\mathrm{M}}}} \cdot \sum_{j=1}^{N_{\mathrm{V}, \mathrm{C}_{\mathrm{M}}}} R\left(C_{j}\right) \\
\varepsilon_{\mathrm{V}, \mathrm{C}_{\mathrm{M}}}=\frac{1}{N_{\mathrm{V}, \mathrm{C}_{\mathrm{M}}}} \cdot \sum_{j=1}^{N_{\mathrm{V}, \mathrm{C}_{\mathrm{M}}}}\left(R\left(C_{j}\right)-R_{\mathrm{V}, \mathrm{C}_{\mathrm{M}}}\right)^{2}
\end{gathered}
$$

We introduce the Chroma spacing coefficient, $\varepsilon_{\mathrm{V}, \mathrm{R}}$, to measure to which degree the rings of Munsell Chroma, $C_{\mathrm{M}, \mathrm{j}}$, are uniformly spaced at a given constant Munsell Value, and computed as follows:

$$
\varepsilon_{\mathrm{V}, \mathrm{R}}=\frac{1}{n_{\mathrm{V}, \mathrm{C}_{\mathrm{M}}}} \cdot \sum_{j=1}^{n_{\mathrm{V}, \mathrm{C}_{\mathrm{M}}}}\left(\frac{R_{\mathrm{V}, \mathrm{C}_{\mathrm{M}, \mathrm{j}}}-C_{\mathrm{M}, \mathrm{j}}}{C_{\mathrm{M}, \mathrm{j}}}\right)^{2}
$$

where $n_{\mathrm{V}, \mathrm{C}_{\mathrm{M}}}$ is the number of Chroma rings used to compute the coefficient for a given Value.

The uniformity of the hue-spacing in a given Chroma locus is evaluated by means of the hue deviation coefficient, $\varepsilon_{\mathrm{H}, \mathrm{V}, \mathrm{C}_{\mathrm{M}}}$, defined as follows:

$$
\varepsilon_{\mathrm{H}, \mathrm{V}, \mathrm{C}_{\mathrm{M}}}=\frac{1}{N_{\mathrm{V}, \mathrm{C}_{\mathrm{M}}}} \cdot \sum_{j=1}^{N_{\mathrm{V}, \mathrm{C}_{\mathrm{M}}}}\left(\frac{\Delta H\left(C_{j}\right)}{R\left(C_{j}\right)}-\frac{2 \pi}{N_{\mathrm{V}, \mathrm{C}_{\mathrm{M}}}}\right)^{2}
$$

where:

$$
\Delta H\left(C_{j}\right)=\left\|\mathrm{TD}\left(C_{j}\right)-\mathrm{TD}\left(C_{j+1}\right)\right\|
$$

Note that $\Delta H\left(C_{j}\right)$ is not a hue increment, but the distance between two consecutive hues measured in the normalized TD plane. In incomplete rings $\Delta H\left(C_{j}\right)$ and $\varepsilon_{\mathrm{H}, \mathrm{V}, \mathrm{C}_{\mathrm{M}}}$ are redefined to avoid regions where hues are missing.

The lower the coefficients for circularity, $\varepsilon_{\mathrm{V}, \mathrm{C}_{\mathrm{M}}}$, hue spacing, $\varepsilon_{\mathrm{H}, \mathrm{V}, \mathrm{C}_{\mathrm{M}}}$, and Chroma spacing, $\varepsilon_{\mathrm{V}, \mathrm{R}}$, the better the circularity and the uniformity in hue and Chroma.

\section{Eccentricity and Stability}

The eccentricity of the constant Munsell Chroma loci were evaluated by means of the ring's center eccentricity, $e_{\mathrm{V}}\left(C_{0, C_{\mathrm{M}}}\right)$, measured from the global "center of gravity" for that Value, that is:

$$
e_{\mathrm{V}}\left(C_{0, \mathrm{C}_{\mathrm{M}}}\right)=\left\|\mathrm{TD}\left(C_{0, \mathrm{C}_{\mathrm{M}}}\right)-\mathrm{TD}\left(C_{0}\right)\right\|
$$

where $\operatorname{TD}\left(C_{0, C_{\mathrm{M}}}\right)$ is the center of gravity of the Chroma $C_{\mathrm{M}}$ ring for Value $V$, defined as follows:

$$
\operatorname{TD}\left(C_{0, \mathrm{C}_{\mathrm{M}}}\right)=\frac{1}{N_{\mathrm{V}, \mathrm{C}_{\mathrm{M}}}} \cdot \sum_{j=1}^{N_{\mathrm{V}, \mathrm{C}_{\mathrm{M}}}} \mathrm{TD}\left(C_{j, \mathrm{C}_{\mathrm{M}}}\right)
$$

Finally, to quantify the stability of the centers of gravity for Munsell Value $V$, we use a coefficient $\varepsilon_{\mathrm{V}, \mathrm{e}}$, given by:

$$
\varepsilon_{\mathrm{V}, \mathrm{e}}=\frac{1}{n_{\mathrm{V}, \mathrm{C}_{\mathrm{M}}}} \cdot \sum_{j=1}^{n_{\mathrm{V}, \mathrm{C}_{\mathrm{M}}}} e_{\mathrm{V}}\left(C_{0, \mathrm{C}_{\mathrm{M}}}\right)^{2}
$$

1. Fairchild MD. Refinement of the RLAB colour space. Colour Res Appl 1996;21:338-346.

2. Fairchild MD, Berns RS. Image colour-appearance specification through extension of CIELAB. Colour Res Appl 1993;18:178-190.

3. Hunt RWG. Revised colour-appearance model for related and unrelated colours. Colour Res Appl 1991;16:146-165.

4. Hunt RWG. An improved predictor of colourfulness in a model of colour vision. Colour Res Appl 1994;19:23-26.

5. Luo MR, Lo MC, Kuo WG. The LLAB(l:c) colour model. Colour Res Appl 1996;21:412-429.

6. Nayatani Y, Hashimoto K, Takahama K, Sobagaki H. A non-linear colour-appearance model using Estévez-Hunt-Pointer primaries. Colour Res Appl 1987;12:231-242.

7. Nayatani Y, Takahama K, Sobagaki H, Hashimoto K. Colour-appearance model and chromatic-adaptation transform. Colour Res Appl 1990;15:210-221.

8. Boynton RM. A system of photometry and colourimetry based on cone excitations. Colour Res Appl 1986;11:244-252.

9. De Valois RL, De Valois KK. A multi-stage colour model. Vision Res 1993;33:1053-1065.

10. De Valois RL, De Valois KK, Switkes E, Luke M. Hue scaling of isoluminant and cone-specific lights. Vision Res 1997;37:885897.

11. Guth SL, Massof RW, Benzschawel T. Vector model for normal and dichromatic vision. J Opt Soc Am 1980;70:197-212.

12. Guth SL. Model for colour vision and light adaptation. J Opt Soc Am A 1991;8:976-993; Erratum J Opt Soc Am A 1992;9:344.

13. Guth SL. Unified model for human colour perception and visual adaptation II. Proc SPIE-Int Soc Opt Eng 1993;1913:440-448.

14. Guth SL. ATD model for colour vision I: Background. Proc SPIEInt Soc Opt Eng 1994;2170:149-152.

15. Guth SL. ATD model for colour vision II: Applications. Proc SPIEInt Soc Opt Eng 1994;2170:153-162.

16. Guth SL. Further applications of the ATD model for colour vision. Proc SPIE-Int Soc Opt Eng 1995;2414:12-26.

17. Valberg A, Seim T, Lee BB, Tryti J. Recontruction of equidistant colour space from responses of visual neurones of macaques. J Opt Soc Am A 1986;3:1726-1734.

18. Luo MR, Hunt RWG. The structure of the CIE 1997 colour appearance model (CIECAM97s). Colour Res Appl 1998;23:138-146. 
19. CIE Publ. No. 116:1995. Industrial Colour Difference Evaluation. Vienna: CIE Central Bureau; 1995.

20. Hurvich LM, Jameson D. An opponent-process theory of colour vision. Psych Rev 1957;64:384-404.

21. Ingling CR, Tsou BH. Orthogonal combinations of the three visual channels. Vision Res 1977; 17:1075-1082.

22. CIE Publ. No. 159:2004. A Colour Appearance Model for Colour Management Systems: CIECAM02. Vienna: CIE Central Bureau; 2004.

23. Luo MR, Li C, Cui G. Combining colour appearance model with colour difference formula. The 10th Congress of the International Colour Association (AIC'05), Granada, Spain, May 2005. p 235-240.

24. Luo MR, Cui G, Li C. Uniform Colour Spaces Based on CIECAM02 Colour Appearance Model. Colour Res Appl 2006;31: 320-330.

25. Gómez-Chova J, Capilla P, Artigas JM, Luque MJ, Felipe A. ATTD: A new colour vision model based on the physiology of the visual system. The 10th Congress of the International Colour Association (AIC'05), Granada, Spain, May 2005. p 1007-1010.

26. Gómez-Chova J, Artigas JM, Capilla P, Felipe A, Luque MJ. Testing the perfomance of ATTD colour vision model. The 10th Congress of the International Colour Association (AIC'05), Granada, Spain, May 2005. p 1011-1014.

27. Indow T. Global colour metrics and colour-appearance system. Colour Res Appl 1980;5:5-12.

28. Guan S, Luo MR. Investigation of parametric effects using small colour differences. Colour Res Appl 1999;24:331-343.

29. Luo MR, Cui G, Rigg B. The development of the CIE 2000 colour-difference formula: CIEDE2000. Colour Res Appl 2001;26: 340-350.

30. Zhu SY, Luo MR, Cui G. New experimental data for investigating uniform colour spaces. The 9th Congress of the International Colour Association (AIC Colour 2001), Rochester, New York, June 2001. p 626-629.

31. MacAdam DL. Uniform colour scales. J Opt Soc Am 1974;64:16191702.

32. Guan SS, Luo MR. A colour-difference formula for assessing large colour differences. Colour Res Appl 1999;24:344-355.

33. Badu S. Large Colour Differences Between Surface Colours, Ph. D. Thesis. Bradford: University of Bradford; 1986.

34. Pointer MR, Attridge GG. Some aspects of the visual scaling of large colour differences. Colour Res Appl 1997;22:298-307.

35. Newhall SM. Preliminary report of the O.S.A. Subcommittee on the spacing of the Munsell colours. J Opt Soc Am 1940;30:617-645.

36. Newhall SM, Nickerson D, Judd D. Final report of the O.S.A. Subcommittee on spacing of the Munsell colours. J Opt Soc Am $1943 ; 33: 385-418$
37. García PA, Huertas R, Melgosa M, Cui G. Measurement of the relationship between perceived and computed colour differences. J Opt Soc Am A 2007;24,7:1823-1829.

38. Melgosa M, Huertas R, Rivas MJ, García PA, González A, Vik M, Cui C. Significación estadística de las correcciones introducidas en las fórmulas de diferencia de colour CIE94 y CIEDE2000. VIII Congreso Nacional de Colour 2007, Madrid, Spain, September 2007.

39. Malo J, Luque MJ. ATTDSJV toolbox for COLORLAB http:// www.uv.es/vista/vistavalencia/software/colorlab.html.

40. Smith VC, Pokorny J. Spectral sensitivity of the foveal cone photopigments between 400 and $500 \mathrm{~nm}$. Vision Res 1975;15:161-171.

41. Naka KI, Rushton WAH. S-potentials from colour units in the retina of fish (cyprinidae). J Physiol 1966;185:536-555.

42. Wiesel TN, Hubel DH. Spatial and chromatic interactions in the lateral geniculate body of the rhesus monkey. J Neurophysiol 1966;29: $1115-1156$.

43. Gouras P, Zrenner E. Colour coding in primate retina. Vision Res 1981;21:1591-1598.

44. Derrington AM, Krauskopf J, Lennie P. Chromatic mechanisms in lateral geniculate nucleus of macaque. J Physiol 1984;357:241265 .

45. Casagrande VA. A third parallel visual pathway to primate area V1. Trends Neurosci 1994;17:305-310.

46. Dacey DM, Lee BB. The blue-on opponent pathway in primate retina originates from a distinct bistratified ganglion cell type. Nature 1994;367:731-735.

47. De Valois RL. Neural coding of colour. In: Chalupa LM, Werner JM, editors. Visual Neuroscience. Cambridge: The MIT Press; 2004. p 1003-1016.

48. Lee BB. Pathways to colour in the retina. The 10th Congress of the International Colour Association (AIC'05), Granada, Spain, May 2005. p 163-168.

49. DeMonasterio FM, Gouras P. Functional properties of ganglion cells of the rhesus monkey retina. J Physiol 1975;251:167-195.

50. Livingstone MS, Hubel DH. Anatomy and physiology of a colour system in the primate visual cortex. J Neurosci 1984;4:309-356.

51. Ts'o DY, Gilbert CD. The organization of chromatic and spatial interctions in the primate striate cortex. J Neurosci 1988;8:17121728.

52. Conway BR. Spatial structure of cone inputs to colour cells in alert macaque primary visual cortex. J Neurosci 2001;21:2768-2783.

53. Landisman CE, T'so DY. Colour processing in macaque striate cortex: Electrophysiological properties. J Neurophysiol 2002;87:31383151.

54. Seim T, Valberg A. Towards a uniform colour space. A better formula to describe the Munsell and OSA colour scales. Colour Res Appl 1986;11:11-24. 